\title{
A therapy dog's impact on daytime activity and night-time sleep for older persons with Alzheimer's disease - A case study
}

\author{
Anna Swall ${ }^{1,2}$, Ingegerd Fagerberg ${ }^{1,3}$, Britt Ebbeskog ${ }^{1}$, Carina Lundh Hagelin ${ }^{2,4,5}$ \\ 1. Department of Neurobiology, Caring Science and Social Science, Karolinska Institutet, Sweden. 2. Sophiahemmet \\ University, Sweden. 3. Department of Health Care Science, Ersta Sköndal University College, Sweden. 4. Department of \\ Learning, Informatics, Management and Ethics, Medical Management Center, Karolinska Institutet, Sweden. 5. \\ Stockholms Sjukhem Foundation, Sweden.
}

Corespondence: Anna Swall. Address: Sophiahemmet University, Lindstedtsväg 8, 11486 Stockholm, Sweden. Email: anna.swall@shh.se

Received: May 7, 2014

Accepted: August 28, $2014 \quad$ Online Published: September 14, 2014

DOI : $10.5430 /$ cns.v2n4p80

URL: http://dx.doi.org/10.5430/cns.v2n4p80

\section{Abstract}

Background: Animal-Assisted Therapy using dogs have been described as having a calming effect, decrease sundowning and blood-pressure in persons with Alzheimer's disease. The aim was to investigate how continuous and scheduled visits by a prescribed therapy dog affected daytime and night-time sleep for persons with Alzheimer's disease.

Methods: In this case study, registration of activity and sleep curves was conducted from five persons with moderate to severe Alzheimer's disease living at a nursing home, over a period of 16 weeks using an Actiwatch. Data was analysed with descriptive statistics.

Result: The study shows no clear pattern of effect on individual persons daytime activity and sleep when encounter with a therapy dog, but instead points to a great variety of possible different effects that brings an increased activity at different time points, for example during night-time sleep.

Conclusions: Effects from the use of a Animal-Assisted Therapy with a dog in the care of persons with Alzheimer's disease needs to be further investigated and analysed from a personcentred view including both daytime and nightime activities.

\section{Key words}

Alzheimer’s disease, Animal-assisted therapy, Activity, Nursing, Sleep

\section{I ntroduction}

Moderate to severe Alzheimer's disease (AD) may cause behavioural and psychological symptoms of dementia (BPSD) ${ }^{[1-3]}$, and result in an everyday life at an institution. This might give rise to experiencing a feeling of being restricted, trapped or overprotected. These feelings might result in a struggle to get home ${ }^{[4]}$, with wandering and checking doors in an attempt to get out ${ }^{[5]}$. Sundown syndrome among persons with AD exhibits wandering and agitative behaviour because of a decreased ability to cope with external stimuli towards evening. Sundowning frequently occurs between 7 and 
$10 \mathrm{pm}$, but can appear 24 hours/day ${ }^{[6]}$, and the agitation may worsens in winter ${ }^{[7]}$. Disturbed sleep frequently occurs, affecting about $50 \%$ of all patients with $\mathrm{AD}^{[8]}$. The wakefulness after sleep onset at night increases with the severity of the disease, and is also one of the major reasons for institutionalization for persons with dementia ${ }^{[9]}$.

Humans and animals are described as being deeply connected from way back in time ${ }^{[10,11]}$. The use of animals e.g. dogs, cats and fish in the care of older persons has increased over past years. Animal -Assisted Therapy (AAT) uses animals in situations to heal, e.g. dealing with psychological and emotional problems ${ }^{[11]}$. For persons with dementia, AAT with a therapy dog is described as having a positive effect ${ }^{[12]}$, for example decreasing anxiety and lowering blood pressure ${ }^{[13]}$, and increasing social behaviour manifested in smiles, talk and eye contact ${ }^{[14-17]}$. Decreased depressive symptoms ${ }^{[18]}$, increased activity ${ }^{[19]}$ and quality of life ${ }^{[20]}$ are also reported. Persons with AD spending time with a dog show lower frequency of verbal aggressiveness and agitative behaviour ${ }^{[21-23]}$. Churchill et al. ${ }^{[24]}$ found that having a dog present in the evening decreased the sundowning effect and minimized agitative behaviour before bedtime. McCabe et al. ${ }^{[25]}$ reports that persons with AD having close contact with a dog for one month showed a decrease in behavioural disturbance in the evening. In Sweden a special training started in 2008, whereby a dog and a handler train together to gain an AAT team diploma. During the training the dogs are thoroughly tested in different situations to manage to be together with and function well with persons with dementia. The use of AAT with a therapy dog is today established in more than 40 counties in Sweden and persons with AD can be prescribed scheduled visits by a dog and its handler in some nursing homes, and other health care facilities. A visit might be prescribed for a need to increase or decrease activity. To the best of our knowledge, no research has yet been conducted that investigates the activity and sleep of persons with AD in connection with AAT with a therapy dog. The aim was to investigate how continuous and scheduled visits by a prescribed therapy dog affected the daytime and night-time activity of persons with AD.

\section{Design and method}

This case study followed persons with AD who were prescribed scheduled AAT with a therapy dog team over a period of 16 weeks. By using a longitudinal case method ${ }^{[26]}$ we followed each person individually for a one-week baseline (before the visits of the therapy dog teams), during 10 weeks of scheduled visits (one visit/week) and for a five-week follow-up after the visits ended.

\subsection{Participants}

Five persons diagnosed with AD and a Minimental score examination (MMSE) score between 1and 17 and prescribed AAT with a therapy dog team were eligible for participation. Three persons sat in a wheel chair, and two walked with support. Inclusion criteria were that the persons should not have had therapy dog visits before. As the prescription of therapy dog visits was based on individual needs there were therefore differing aspects to consider. One potential participant was excluded from the study during the first visit for ethical reasons, because of a strong negative reaction to the dog.

\subsection{Measurements}

An Actigraf 7 (Actiwatch ${ }^{\circledR}$;Cambridge Neurotechnology, Cambridge, UK) was used to register the person's physical daytime activity, sleep onset as well as night-time activity for 24 hours a day. The Actiwatch ${ }^{\circledR}$ is the size of a wristwatch and can register the speed and intensity of the person's arm movements. The Actiwatch ${ }^{\circledR}$ was carried on the non-dominant wrist during the whole study period, even when taking a bath or shower. Data is generated for processing in the form of graphs of activity for selected time points (epochs) (see Figure 1). In the present study recording of counts every minute was chosen for these epochs. A score of 40 counts/minute indicates the wearer is awake ${ }^{[27]}$, and the graphs are used to estimate the individual's daytime activity, sleep onset and waking times. The Actiwatch ${ }^{\circledR}$ was chosen due to its convenient minimal size and weight, and the fact that it only had to be removed once a month for registering of data. The Actiwatch ${ }^{\circledR}$ has been used in studies of both activity and sleep for persons with dementia ${ }^{[28-31]}$ and has been validated and reliability 
tested in earlier studies and found to accurately record levels of activity (movements of the arm) ${ }^{[28,29]}$, thus proving a suitable instrument for use in persons with $\mathrm{AD}$ and other dementias ${ }^{[30,31]}$. The participants cognitive impairment was assessed using the Mini-Mental State Examination (MMSE 0-30 p) ${ }^{[32]}$, which indicates a grade of impairment from dementia (1-17 p) among the participants, and follows the MMSE grade for moderate (MMSE 10-20) to severe (MMSE $0-9)$ dementia.

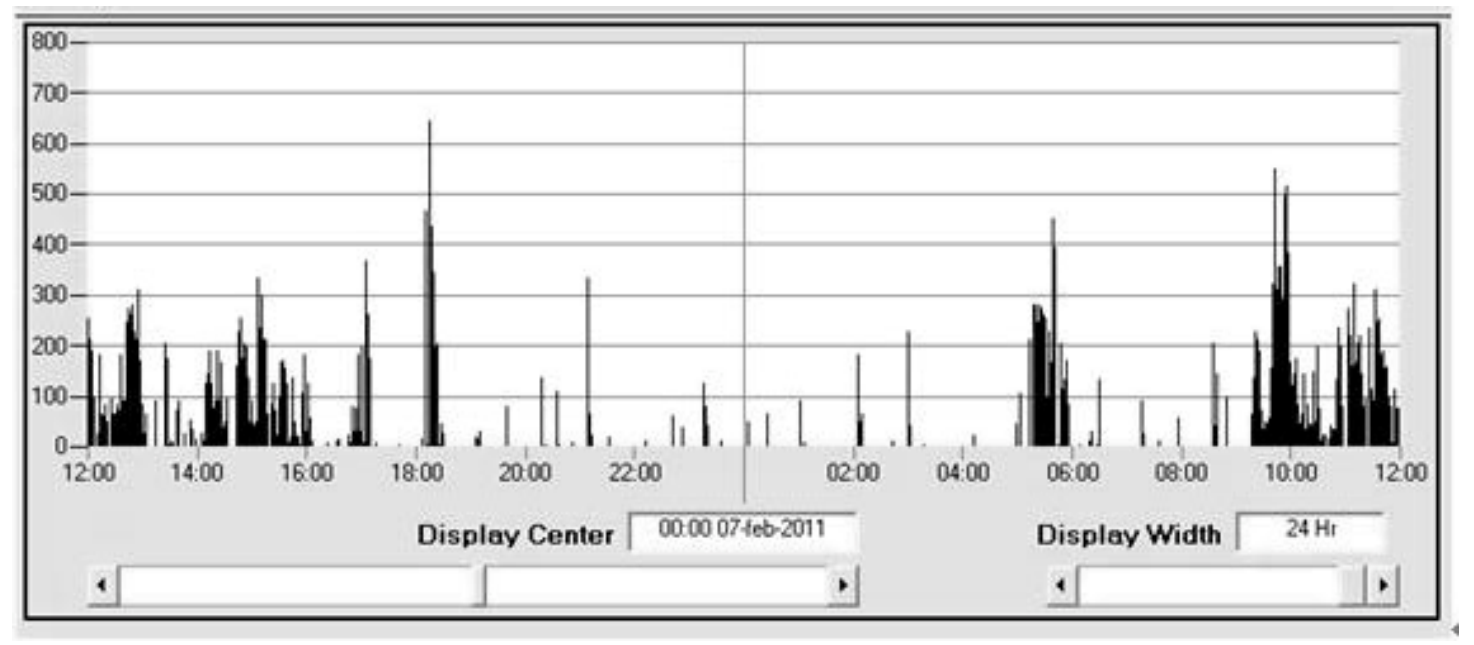

Figure 1. Activity curves person 1, transferred in to the Actiwatch software

\subsection{Data collection}

The participants were individually prescribed AAT with a therapy dog and then followed and assessed ${ }^{[26]}$. Recording using the Actiwatch ${ }^{\circledR}$ started one week before the first visits of the therapy dog (baseline), continued during the period of therapy dog visits (10 weeks), and during the follow-up period (5 weeks) - a total of 16 weeks. Data was recorded each minute from baseline to a total of 16 weeks. Daytime activity and night-time sleep were analysed separately for each person, as well as individual night-time sleep onset and cessation. Day and nights' beginning and end were determined based on activity curves in the Actiwatch software, where activity lower than 40 counts / minute indicated sleep ${ }^{[27]}$. The first author (AS) transferred data from the actiwatches to a computer every fourth week and checked the functions of the watches.

\subsection{Procedure}

The case study is a part of a larger longitudinal research project following persons with AD over a period of 6 months where AAT with a therapy dog team is used ${ }^{[37]}$. Data for the present study was gathered over a period of 16 weeks between February and September 2011. Study centre is a municipal nursing home in a metropolitan area in Sweden, comprising four inpatient wards with 20 persons with dementia on each ward. The particular AAT team had been established for two years at the nursing home and the visits took place in a specially adapted room with dog toys, pictures of dogs, and where activities included throwing balls, giving sweets, as well as cuddling and talking to the dog took place. The trained therapy dog was a Labrador (11 years old) and, occasionally an apprentice dog a dachshund (7 years old) was present. The dog handler made sure that only one dog at the time interacted with the person at the visits. The dog handler was present at all time and sometimes encourages the persons with $\mathrm{AD}$ to give the dog commands to perform and to do tricks. A registered nurse working on each ward prescribed visits for a specific individual purpose, for example to increase a patient's activity level or to decrease aggressive or wandering behaviour. The night-time sleep was not mentioned, however to be able to analyse effect on activity levels daytime and night-time activity were separated and we worked with the assumption that during night-time the activity should preferably be low and the person sleeping. When the therapy dog team received a prescription for a person that needed therapy dog visits, the visits started one week later. 
The persons prescribed an AAT team with a therapy dog all had had experience of dogs earlier in life. The AAT handler planned a schedule of ten visits (one visit/week), following recommendation from the training program and each visit varied between 30 minutes and one hour and was tailored to meet the individual's specific needs based on the prescribed purpose for each person. The purpose of the visits could also change during the course of each visit depending on the daily condition and specific needs of the person with AD.

\subsection{Statistical analysis}

Data from the Actiwatch ${ }^{\circledR}$ was transferred to a computer via a software reader recommended by the instrument manual, reproducing data as activity curves (counts/minute for each person), Figure 1. Data was analysed by descriptive analysis by Excel ${ }^{\circledR}$ software. Individual activity levels and characteristics were recorded as a mean value (m) and standard deviation (SD) of collected counts/minute per week (including one week baseline) for both daytime activity and sleep at night. To be able to investigate effects during the visit with the AAT team the activity was measured 1 hour before the visit, for the 30 -45 minutes of the visit (each visit lasted 30-60 minutes), and during 1 hour after each visit. These data was compared with video observations (VIO) done at every visit to get a view of what kind of activity the visit mostly comprised of. The activity from the VIO are summarized for each person in table 1, 2, 3, 4, 5 and is marked; a) playing, b) talking, and c) cuddling.

\subsection{Ethical considerations}

The study was approved by the Regional Board of Research Ethics 2010/220-31/1. Since all persons participating had moderate to severe $\mathrm{AD}$, a next of kin as well as the caregivers at the ward were informed both in writing and verbally of the aim of the study and the function of the Actiwatch ${ }^{\circledR}$. The person's next of kin was also given written information about the study and then asked to sign a proxy consent ${ }^{[33]}$.

\section{Results}

A total of five older persons, one man and four women, diagnosed with AD and prescribed AAT with a therapy dog were included in this case study. The age of the participants ranged from 89-95 years (see Table 1). The MMSE showed participants as having moderate $(n=2)$ to severe $(n=3)$ dementia ranged from 1-17 at the start of the study (see Table 1$)$.

Table 1. Demographic data for each participant

\begin{tabular}{lllllll}
\hline Participants & Age & Gender & MMSE baseline & Day time activity purpose & Daytime end & Daytime start \\
\hline 1 & 95 & Female & 9 & $\boldsymbol{\uparrow}$ & $8.00 \mathrm{pm}$ & $7.00 \mathrm{am}$ \\
2 & 89 & Female & 9 & $\boldsymbol{\Downarrow}$ & $7.00 \mathrm{pm}$ & $7.00 \mathrm{am}$ \\
3 & 95 & Female & 1 & $\boldsymbol{\uparrow}$ & $7.00 \mathrm{pm}$ & $7.00 \mathrm{am}$ \\
4 & 91 & Female & 17 & $\boldsymbol{\uparrow}$ & $8.00 \mathrm{pm}$ & $9.00 \mathrm{am}$ \\
5 & 89 & Male & 14 & $\boldsymbol{\rightarrow}$ & $7.00 \mathrm{pm}$ & $9.00 \mathrm{am}$ \\
\hline
\end{tabular}

$\uparrow$ represents an intention for the Animal-Assisted therapy team period to increase the person with AD’s daytime activity.

$\downarrow$ represents an intention for the Animal-Assisted therapy team period to decrease the person with AD’s daytime activity.

MMSE=Mini mental state examination

Data showed a variation in both daytime activity and nighttime sleep both between and within individuals during the entire study period(see Table 2, 3). In this case-study each individual were followed individually and participants are presented with fictitious names. Mrs. Anderson (Person 1): Mrs. Brown (Person 2): Mrs. Carlson (Person 3): Mrs. Daniels (Person 4): Mr. Edgar (Person 5). 
Table 2. Mean value and standard deviation (SD) for counts per minute for day time activity at baseline, and for AAT visits weeks 1-10 and follow-up weeks 1-5

\begin{tabular}{|c|c|c|c|c|c|}
\hline & $\begin{array}{l}\text { Person } 1 \uparrow \\
\text { Mean (SD) }\end{array}$ & $\begin{array}{l}\text { Person } 2 \downarrow \\
\text { Mean (SD) }\end{array}$ & $\begin{array}{l}\text { Person } 3 \uparrow \\
\text { Mean (SD) }\end{array}$ & $\begin{array}{l}\text { Person } 4 \uparrow \\
\text { Mean (SD) }\end{array}$ & $\begin{array}{l}\text { Person } 5 \rightarrow \\
\text { Mean (SD) }\end{array}$ \\
\hline Baseline- week & $80,6(126,4)$ & $54,9(103,7)$ & $15,4(52,5)$ & $64,1(101,3)$ & $33,8(63,7$ \\
\hline Day 1 & $78,8(126,7)$ & $122,8(154,8)$ & $28,9(95,6)$ & $118,4(116,2)$ & $33,4(50,1)$ \\
\hline Day 2 & $78,5(113,1)$ & $30,1(75,0)$ & $11,1(27,8)$ & $40,3(82,2)$ & $31,2(54,9)$ \\
\hline Day 3 & $71,3(107,8)$ & $57,6(106,9)$ & $10,8(30,9)$ & $73,7(105,2)$ & $24,1(46,3)$ \\
\hline Day 4 & $58,4(95,3)$ & $35,3(73,8)$ & $14,6(43,8)$ & $73,3(104,2)$ & $52,2(83,7)$ \\
\hline Day 5 & $85,4(121,3)$ & $47,1(89,4)$ & $6,6(27,6)$ & $71,5(107,7)$ & $27,0(55,0)$ \\
\hline Day 6 & $110,9(144,1)$ & $85,4(131,0)$ & $18,6(83,2)$ & $31,8(62,5)$ & $37,8(71,3)$ \\
\hline Day 7 & $79,6(159,3)$ & $45,9(86,2)$ & $24,8(47,9)$ & $71,7(114,4)$ & $30,6(66,1)$ \\
\hline \multicolumn{6}{|l|}{ AAT visits } \\
\hline W 1 & $116,1(167,5)$ & $50,7(97,6)$ & $21,2(52,7)$ & $54,3(93,9)$ & $42,1(97,8)$ \\
\hline W 2 & $147,2(189,2)$ & $70,6(129,6)$ & $14,9(42,6)$ & $46,9(85,5)$ & 49,9 $(95,6)$ \\
\hline W 3 & $155,4(204,6)$ & $61,5(119,5)$ & $12,2(37,4)$ & $54,8(93,0)$ & $44,4(80,1)$ \\
\hline W 4 & $184,2(222,4)$ & $64,7(136,6)$ & $10,3(34,2)$ & $62,2(109,3)$ & $33,7(71,5)$ \\
\hline W 5 & $164,9(217,6)$ & $44,2(96,0)$ & $16,2(43,6)$ & $50,7(88,9)$ & $35,4(71,3)$ \\
\hline W 6 & $138,7(195,0)$ & $36,3(82,7)$ & $19,0(53,7)$ & $53,1(96,6)$ & $32,1(78,9)$ \\
\hline W 7 & $115,3(172,9)$ & $41,9(85,6)$ & $15,9(41,7)$ & $53,9(95,4)$ & $30,6(58,3)$ \\
\hline W 8 & $101,0(160,1)$ & $56,0(102,1)$ & $15,4(38,9)$ & $61,2(100,0)$ & $31,7(64,1)$ \\
\hline W 9 & $118,4(171,1)$ & $42,8(96,8)$ & $17,8(55,9)$ & $51,6(87,3)$ & $30,9(59,4)$ \\
\hline W 10 & $144,3(189,3)$ & $31,3(98,1)$ & $10,3(34,8)$ & $72,2(105,6)$ & $48,6(93,5)$ \\
\hline \multicolumn{6}{|l|}{ Follow-up } \\
\hline W 1 & $133,8(178,9)$ & $32,4(69,2)$ & $16,0(41,4)$ & $54,7(91,3)$ & $40,2(79,7)$ \\
\hline W 2 & $144,2(198,5)$ & $24,3(59,9)$ & $17,5(42,5)$ & $59,4(96,4)$ & $26,7(54,7)$ \\
\hline W 3 & $128,4(169,3)$ & $30,0(69,5)$ & $14,0(42,2)$ & $42,8(82,3)$ & $27,7(58,7)$ \\
\hline W 4 & $137,1(177,6)$ & $43,8(91,2)$ & $19,8(48,9)$ & $45,2(85,1)$ & $25,7(56,0)$ \\
\hline W 5 & $121,1(170,7)$ & $27,5(70,5)$ & $18,2(42,9)$ & $42,8(79,1)$ & $37,6(71,7)$ \\
\hline
\end{tabular}

$\uparrow$ represents an intention for the Animal-Assisted therapy team period to increase the person with AD’s day-time activity.

$\downarrow$ represents an intention for the Animal-Assisted therapy team period to decrease the person with AD’s day-time activity.

AAT: Animal-Assisted Therapy

\subsection{Mrs. Anderson}

Mrs. Anderson (Person 1), a 95-year old woman with an MMSE score of 9 (severe AD) was described as not wanting to collaborate in activities because of an injured arm. Mrs. Anderson current activity; sitting in a wheel-chair in the daytime. The aim of using the AAT team with a therapy dog was to increase daytime activity ( $\boldsymbol{\uparrow}$ ) (see Table 1, 2). Daytime activity showed a mean level of 80.6 (see Table 2) counts/minute at baseline and a range between 101.0 counts/minute and 184.2 counts/minute during the period of the therapy dog visits. During the follow-up Mrs. Anderson's daytime activity was registered at 133.8 counts/minute in the first week and then with a mean value of 121.1counts/minute in week 5. Figure 2 shows activity one hour before the therapy dog visit, during the visit for about 30-45 minutes, and one hour after the 
therapy dog visit. The figure also shows the specific activity occurred at the session with the dog e.g. playing, cuddling and talking. For Mrs. Anderson every visit appeared to decrease her activity one hour after the visit compared with before and during the visits. The figure also shows that cuddling occurred most of the visits. Table 3 shows the mean count per minutes during sleep from baseline, the period of therapy dog visits and follow-up period. Sleep at night for Mrs. Anderson was normally between $8.00 \mathrm{pm}$ to $7.00 \mathrm{am}$. Activity at night ranged from a mean level of 37.1 counts/minute at baseline to between 51.0 counts/minute and 163.3 counts/minute during the period of therapy dog visits. Sleep activity during the 5-week follow-up after the period of therapy dog visits varied between 28.5 to 75.4 counts/minute. The patterns of sleep activity during the study period and follow-up are shown at Figure 7.

Table 3. Mean value and standard deviation (SD) for counts per minute during night-time at baseline, and for AAT visits weeks 1-10 and follow-up weeks 1-5

\begin{tabular}{|c|c|c|c|c|c|}
\hline & $\begin{array}{l}\text { Person } 1 \downarrow \\
\text { Mean (SD) }\end{array}$ & $\begin{array}{l}\text { Person } 2 \downarrow \\
\text { Mean (SD) }\end{array}$ & $\begin{array}{l}\text { Person } 3 \downarrow \\
\text { Mean (SD) }\end{array}$ & $\begin{array}{l}\text { Person } 4 \downarrow \\
\text { Mean (SD) }\end{array}$ & $\begin{array}{l}\text { Person } 5 \downarrow \\
\text { Mean (SD) }\end{array}$ \\
\hline Baseline-week & $37,1(96,0)$ & $19,0(62,1)$ & $12,5(35,9)$ & $24,7(73,0)$ & $27,1(62,1)$ \\
\hline Night 1 & $17,7(70,5)$ & $19,1(65,4)$ & $22,7(55,1)$ & $20,6(66,1)$ & $32,5(65,0)$ \\
\hline Night 2 & $4,4(23,3)$ & $15,3(52,6)$ & $5,8(28,9)$ & $22,2(65,4)$ & $29,8(54,6)$ \\
\hline Night 3 & $13,8(53,0)$ & $11,8(44,1)$ & $19,6(40,9)$ & $13,3(58,0)$ & $26,3(59,5)$ \\
\hline Night 4 & $17,8(62,4)$ & $10,7(45,1)$ & $6,1(22,0)$ & $21,9(61,1)$ & $34,1(70,6)$ \\
\hline Night 5 & $54,7(106,9)$ & $51,9(100,9)$ & $10,8(21,4)$ & $32,4(86,4)$ & $2,7(32,7)$ \\
\hline Night 6 & $126,9(143,3)$ & $17,8(55,1)$ & $10,2(32,0)$ & $18,9(55,4)$ & $35,2(72,7)$ \\
\hline Night 7 & $24,5(97,0)$ & $6,6(37,3)$ & - & $43,7(102,1)$ & $29,2(64,7)$ \\
\hline \multicolumn{6}{|l|}{ AAT visits } \\
\hline $\mathrm{W} 1$ & $72,1(160,3)$ & $23,8(74,2)$ & $11,2(32,5)$ & $20,9(64,3)$ & $31,5(72,5)$ \\
\hline W 2 & $96,8(182,5)$ & $23,0(74,7)$ & $12,1(34,2)$ & $26,4(75,2)$ & $40,7(94,3)$ \\
\hline W 3 & $151,0(229,9)$ & $33,5(111,6)$ & $8,2(23,8)$ & $28,0(75,4)$ & $33,1(73,2)$ \\
\hline W 4 & $163,3(248,8)$ & $28,8(95,1)$ & $8,7(27,9)$ & $21,9(67,2)$ & $28,5(66,0)$ \\
\hline W 5 & $123,3(222,1)$ & $35,6(89,3)$ & $10,3(25,6)$ & $20,5(59,1)$ & $27,6(71,4)$ \\
\hline W 6 & $89,0(191,3)$ & $14,9(53,0)$ & $13,7(37,8)$ & $17,9(59,0)$ & $25,1(57,3)$ \\
\hline W 7 & $51,0(135,9)$ & $12,2(53,3)$ & $11,0(29,1)$ & $21,6(65,3)$ & $23,6(54,9)$ \\
\hline W 8 & $61,3(144,2)$ & $12,3(52,1)$ & $12,8(32,4)$ & $25,3(74,0)$ & $27,1(58,8)$ \\
\hline W 9 & $67,9(153,8)$ & $30,3(93,3)$ & $10,6(26,4)$ & $22,9(64,3)$ & $23,3(48,9)$ \\
\hline W 10 & $62,9(146,2)$ & $12,6(45,3)$ & $9,9(23,2)$ & $26,9(71,6)$ & $32,0(81,9)$ \\
\hline \multicolumn{6}{|l|}{ Follow-up } \\
\hline W 1 & $50,4(125,4)$ & $13,0(44,4)$ & $13,1(34,0)$ & $20,8(61,2)$ & $25,8(65,5)$ \\
\hline W 2 & $75,4(172,3)$ & $10,8(43,4)$ & $12,8(31,5)$ & $20,8(62,4)$ & $20,2(44,7)$ \\
\hline W 3 & $62,9(145,2)$ & $9,3(42,9)$ & $11,8(28,2)$ & $12,2(46,4)$ & $19,4(43,9)$ \\
\hline W 4 & $64,1(145,8)$ & $14,3(53,7)$ & $17,0(34,8)$ & $13,9(48,4)$ & $25,1(55,2)$ \\
\hline W 5 & $28,5(88,5)$ & $22,9(68,0)$ & $15,1(35,1)$ & $14,5(50,2)$ & $27,2(57,5)$ \\
\hline
\end{tabular}

$\downarrow$ represents an intention for the Animal-Assisted therapy team period to decrease the person with AD’s night-time activity. For person 3 baseline night 7, the actiwatch was off for one day and night.

AAT: Animal-Assisted Therapy. 


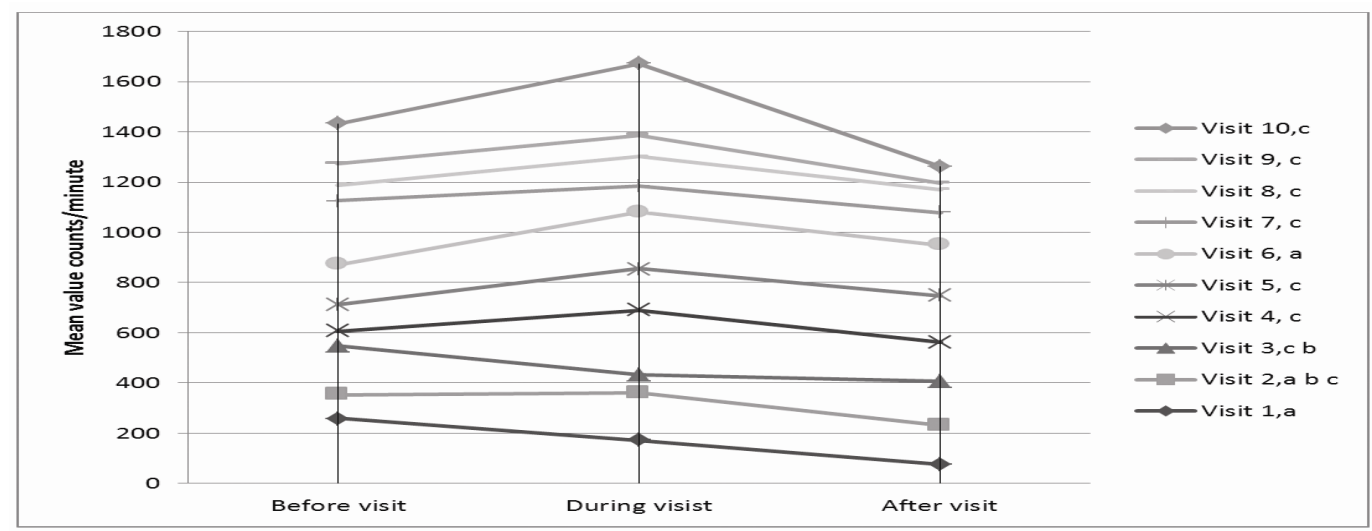

Figure 2. Mrs. Anderson's activity before, during and after each session with the dog. a: playing, b: talking, c: cuddling. The aim for Mrs. Anderson's activity at day time was to increase activity

\subsection{Mrs. Brown}

Mrs.Brown (Person 2), an 89-year old woman with an MMSE score of 9 (severe AD) was described as often showing sadness, anxiety with wandering behaviour and often falling with injuries as a result. Mrs. Brown current activity; walking with support from caregivers during daytime. The aim of the AAT team with a therapy dog for Mrs. Brown was to decrease activity $(\boldsymbol{\Downarrow})$ (see Table 1, 2) and increase harmony. Daytime activity was registered with a mean level of 54.9 counts/minute during baseline week and data then showed a variety in daytime activity with a range between 31.3 counts/minute and 70.6 counts/minute during the period of therapy dog visits. The activity observed during follow-up after the therapy dog period ranged between 24.3 counts/minute and 43.8 counts/minute. Figure 3 shows activity before, during and after the therapy dog visit. The figure also shows the specific activity occurred at the session with the dog e.g. playing, cuddling and talking. For Mrs. Brown the visit with the therapy dog appeared to increase her activity significantly the final visits compared with before and during the visits. However the activity for Mrs. Brown week three and four seemed to decrease compared with the activity during the visit, but increase compared with before the visit. The figure also shows that cuddling occurred most of the visits.

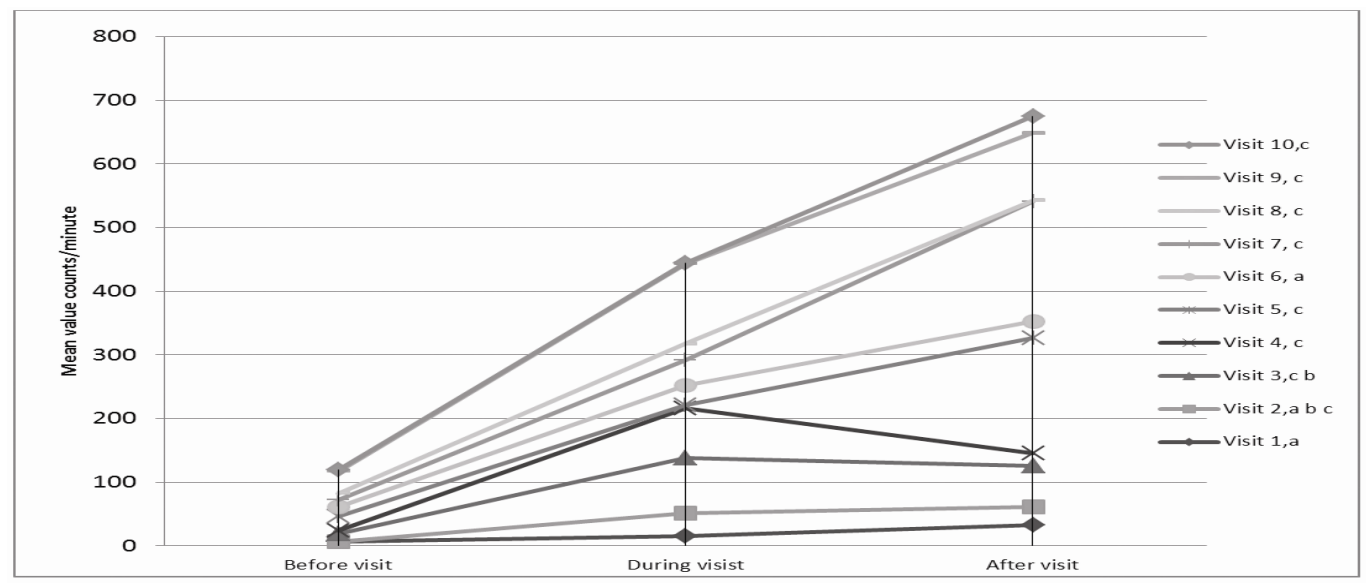

Figure 3. Mrs. Brown's activity before, during and after each session with the dog. a: playing, b: talking, c: cuddling. The aim for Mrs. Brown's activity at day time was to decrease activity

Sleep at night for Mrs. Brown was estimated to be between $7.00 \mathrm{pm}$ to $7.00 \mathrm{am}$. Sleep activity at night was registered at baseline with 19.0 counts/minute then ranged between 12.6 counts/minute to 35.6 counts/minute during the period of 
therapy dog visits. Sleep activity for Mrs. Brown, observed during the 5 weeks of follow-up after the period of the therapy dog visits varied between 9.3 to 22.9 counts/minute.

\subsection{Mrs. Carlson}

Mrs. Carlson (Person 3), a 95-year old woman with an MMSE score of 1 (severe AD) was prescribed a therapy dog because she was tired and inactive. Mrs. Carlson current activity; sitting in a wheel-chair during daytime. The aim of the AAT team with a therapy dog for Mrs. Carlson was to increase activity ( $\uparrow$ ) (see Table 1, 2). She had a mean activity level of 15.4 counts/minute during baseline and ranged between 10.3 counts/minute to 21.2 counts/minute during the period of the therapy dog visits. The activity observed during follow-up ranged between 14.0 counts/minute and 19.8 counts/minute. Figure 4 shows activity before, during and after the therapy dog visit. The figure also shows the specific activity occurred at the session with the dog e.g. playing, cuddling and talking. For Mrs. Carlson every visit appeared to decrease her activity one hour after the visit, and the activity decreases significantly the final seven visits compared with before and during the visits. The figure also shows that cuddling occurred most of the visits.

Sleep activity during night time was estimated to be between $7.00 \mathrm{pm}$ to $7.00 \mathrm{am}$ for Mrs. Carlson. Sleep activity at baseline was registered at 12.5 and ranged between 8.2 counts/minute to 13.7 counts/minute during the period of therapy dog visits. Sleep activity varied between 11.8 and 17.0 counts/minute during follow-up.

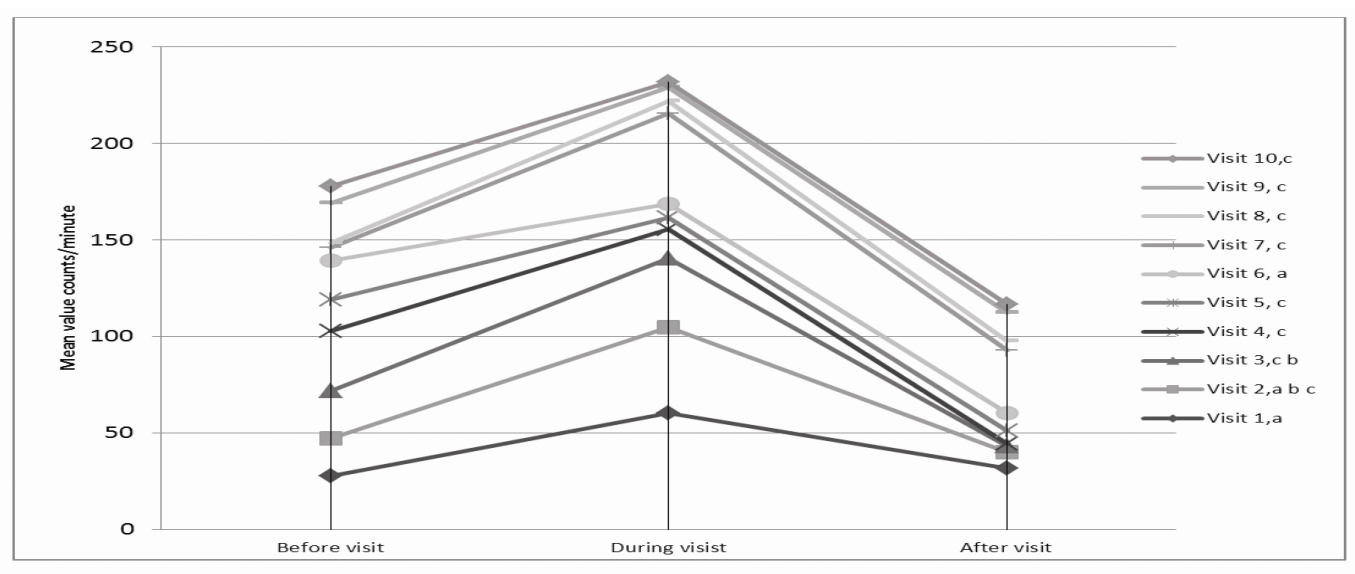

Figure 4. Mrs. Carlson's activity before, during and after each session with the dog. a: playing, b: talking, c: cuddling. The aim for Mrs. Carlson's activity at day time was to increase activity

\subsection{Mrs. Daniels}

Mrs. Daniels (Person 4), a 91-year old woman with an MMSE score of 17 (moderate AD) was prescribed a therapy dog period because she was sad, insecure and tired. Mrs. Daniels current activity; walking by herself during daytime. The aim of the AAT team with a therapy dog for Mrs. Daniels was to increase activity ( $\uparrow$ ) (see Table 1, 2) and for her to feel the closeness of the dog, to create a more meaningful life for her. Daytime activity was recorded with a mean level of 64.1 counts/minute during baseline week and data then showed a variety in daytime activity with a range between 46.9 counts/minute and 72.2 counts/minute during the period of therapy dog visits. The activity observed after the therapy dog period ranged between 42.8 counts/minute and 59.4 counts/minute during follow-up. Figure 5 shows activity before, during, and after the therapy dog visit. The figure also shows the specific activity occurred at the session with the dog e.g. playing, cuddling and talking. For Mrs. Daniels the visit with the therapy dog appeared to decrease her activity one hour after the visit the first four weeks compared with before and during the visits. The figure also shows that cuddling occurred most of the visits. 
Sleep activity at night was estimated to be between $8.00 \mathrm{pm}$ to $9.00 \mathrm{am}$. Sleep activity at baseline was registered at 24.7 counts/minute and then ranged between 17.9 counts/minute to 28.0 counts/minute during the period of therapy dog visits. Sleep activity observed during follow-up after the period of the therapy dog visits varied between 12.2 and 20.8 counts/minute.

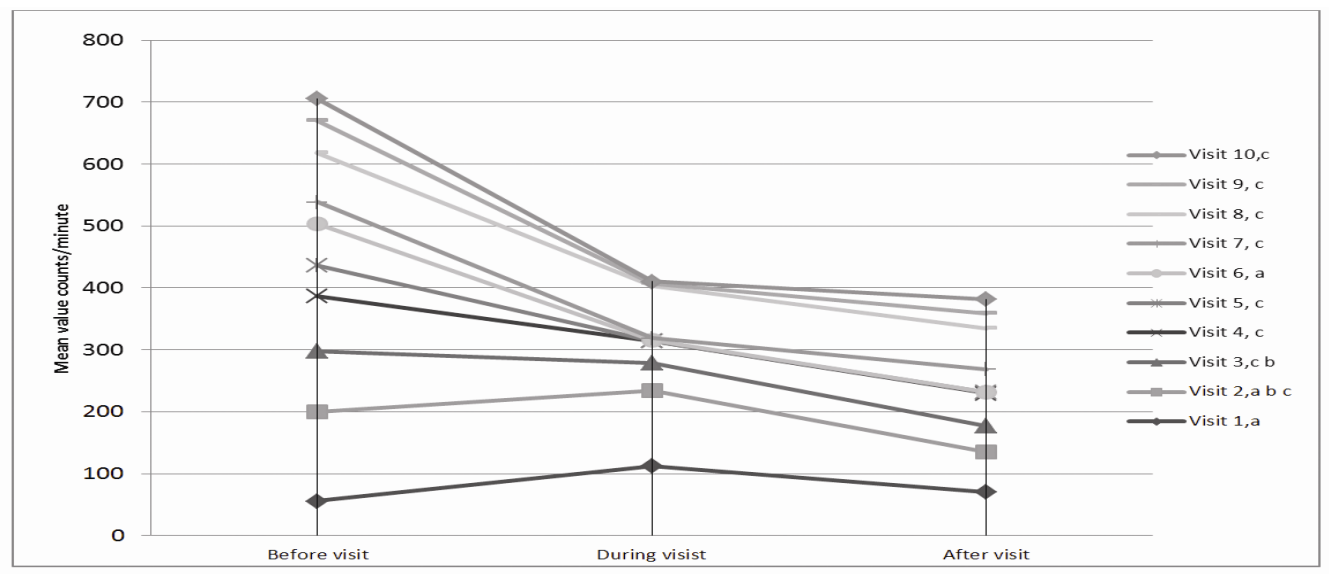

Figure 5. Mrs. Daniel's activity before, during and after each session with the dog. a: playing, b: talking, c: cuddling. The aim for Mrs. Daniel's activity at day time was to increase activity

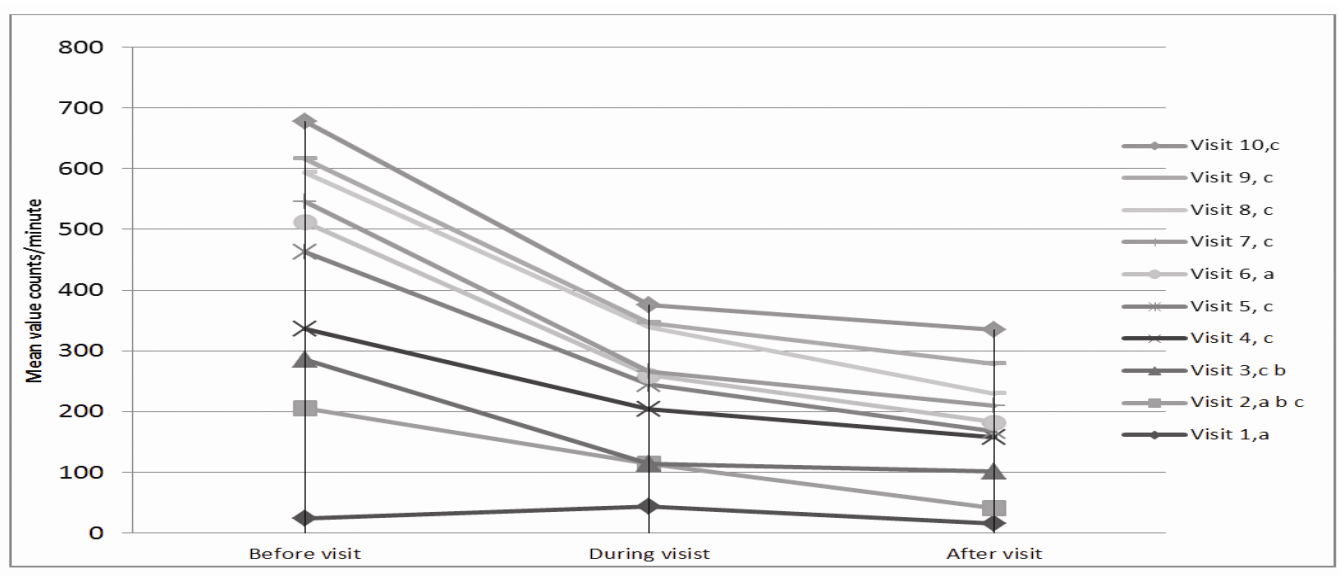

Figure 6. Mr. Edvard's activity before, during and after each session with the dog. a: playing, b: talking, c: cuddling. The aim for Mr. Edvard's activity at day time was to maintain activity

\subsection{Mr. Edgar}

Mr. Edgar (Person 5), an 89-year old man with an MMSE score of 14 (moderate AD) was prescribed a therapy dog period because of frequent disturbed sleep. Mr. Edgar current activity; walking with a walking frame during daytime. The aim of the AAT team with a therapy dog for Mr. Edgar was to maintain activity $(\rightarrow)$ (see Table 1,2 ) during daytime. Daytime activity was registered with a mean level of 33.8 counts/minute during baseline week and data then showed a variety in daytime activity with a range between 30.9 counts/minute and 49.9 counts/minute during the period of therapy dog visits. The activity observed during follow-up after the therapy dog period ranged between 25.7 counts/minute and 40.2 counts/minute. Figure 6 shows activity before, during and after the therapy dog visit. The figure also shows the specific activity occurred at the session with the dog e.g. playing, cuddling and talking. For Mr. Edgar the visit with the therapy dog appeared to decrease his activity one hour after the visit as well as during the visits, compared with before visits. The figure also shows that cuddling occurred most of the visits. Sleep activity at night was estimated to be between $7.00 \mathrm{pm}$ to 9.00 
am for Mr. Edgar. Sleep activity at baseline was registered at 27.1 counts/minute and then ranged between 23.6 counts/minute to 40.7 counts/minute during the period of therapy dog visits. Sleep activity was observed during follow-up after the period of the therapy dog visits varied between 19.4 and 27.2 counts/minute.

The patterns of daytime activity during the study period and follow-up are shown in graphs in Figure 6 and the patterns of sleep activity in Figure 7.

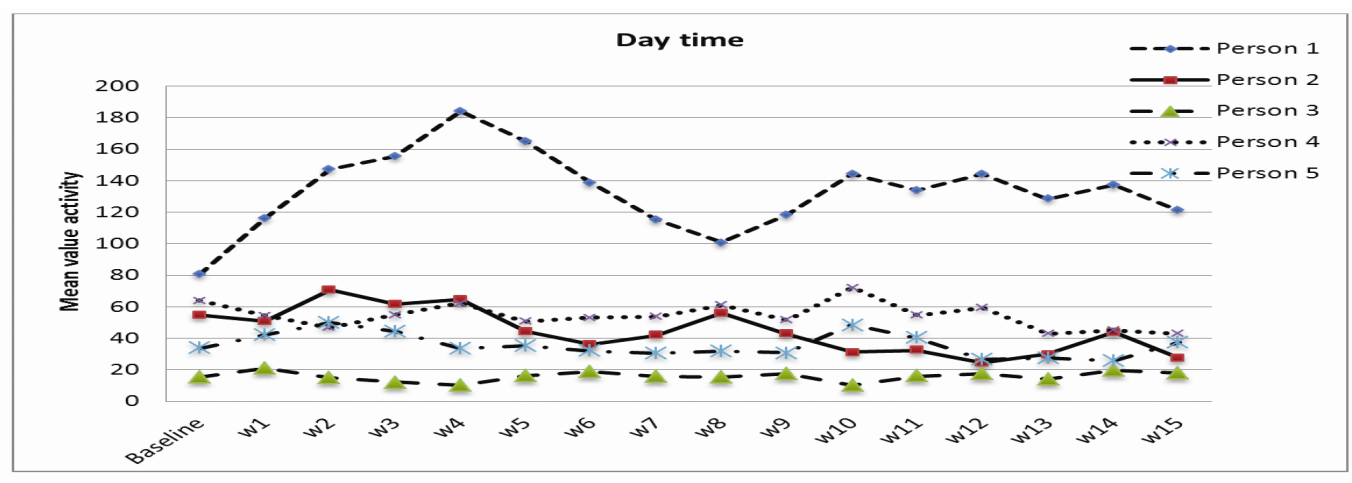

Figure 7. Mean value counts/minute for each week at day-time activity for each participant

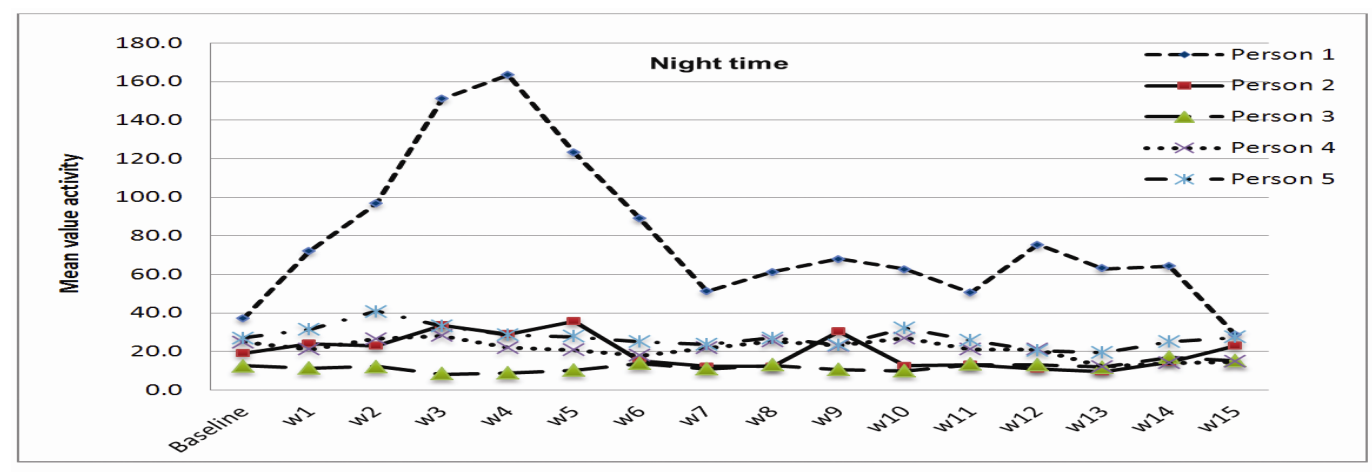

Figure 8. Mean value counts/minute of activity for each week at night-time for each participant

\section{Discussion}

The therapy dog team was prescribed in order to increase or decrease activity, reduce wandering, as well as introvert behaviour, and this motivated us to study the measurement of each person's day and night-time activity. By using the Actiwatch we have been able to follow five persons individually for a period of 16 weeks. This allowed us to record over time the extent of activity in persons with $\mathrm{AD}$, and also the variation found within an individual and between participants. Our investigation of activity and sleep behaviour of persons with moderate to severe AD after scheduled visits with an AAT team and a therapy dog to either increase or decrease activity shows no clear pattern, incongruent with common beliefs and earlier findings suggesting increased social behaviour and activity in the moment with the dog ${ }^{[19]}$. Data shows that levels of daytime activity for participants could be interpreted as individuals being non-active or very active. For activity at night some persons are very inactive and perhaps sleep, while some instead are very active. Activity one hour after each visit by the AAT team was generally lower for most participants (see Figure 2, 4, 5, 6) except for Mrs. Brown (Person 2) (see Figure 3) who for most of the visits (visit 1, 2, 5, 6, 7, 8, 9, 10) got a higher activity one hour after the therapy dog visits. But her night-time activity seemed to vary but in acceptable night-time levels (see Table 3). Mrs. Anderson (Person 1) reached lower levels of activity one hour after each visit (see Figure 2), but in night-time her activity 
levels were generally higher than other participants activity levels at night (see Figure 8, Table 3). It is difficult to know if the participants were sleeping although active. The standard deviation also shows a large scattering in most cases which reinforce the idea that the participants activity vary from longer moments of very low activity to shorter moments of active moments. This could mirror the situation for persons with AD living within an institutional care service. Data also raises the question of sleep quality and fragmentation of sleep and its effect on daytime activity and individual wellbeing. Perhaps the presence of the therapy dog brings individual influences on each person but only for a short period of time during visits and one hour after. It seems that the effect on the activity does not have longer impact than just for the moment and a short time after. If the therapy dog team had visited more often, the activity could be different. This needs to be further investigated, and also to further understand how low activity during the day or an early bedtime like 7.00 p.m. affects sleep at night. An example of the individual effect on daytime and night-time activity is shown in the data for Mrs. Carlson (Person 3) (MMSE-score 1) and for Mrs. Anderson (Person 1) (MMSE-score 9). For Mrs. Carlson (Person 3) the activity was generally lower during daytime than the others. Mrs. Anderson (Person 1) had a generally higher activity during daytime than the others. Investigating the differences between these two individuals might prove interesting, bearing in mind that both have severe AD but differ from each other in both daytime and night-time activity. Several studies ${ }^{[13,16,17,20,21,23,24,34,35]}$ suggest that AAT with a therapy dog influences persons with AD and other dementias in many ways, for example creating increased social activity, joy and well-being, although Kongable et al. ${ }^{[36]}$ found that when a therapy dog moved in to the ward with persons with AD, no significant increases of social behaviour was noted. Swall, Ebbeskog, Lundh Hagelin and Fagerberg ${ }^{[37]}$ also found that the presence of a therapy dog brings moments of sadness difficult for persons with AD to handle. In the present study, we studied activity as a form of effects, which also followed the prescriptions of the AAT. The AAT team with a therapy dog might have had positive effects at a specific time point, with for example increased activity during the day, but on the other hand this could be followed by an increased activity also at other time points, for example during the night (e.g. for Mrs. Anderson, person 1). This study shows no clear straightforward patterns of the AAT team visits according to activity at day time and sleep at night. Possibly during a shorter amount of time but not for a longer perspective. The participating persons had overall a low activity during day time, and some of them also had lower than 40 counts/minute which indicate sleep. One person (Mrs. Anderson, Person 1) does not show any patterns of sleep (lower than 40 counts/minute) during week 1-10. This might influence the well-being in the participating persons. Edvardsson et al. ${ }^{[38]}$ explored the concepts of person-centred care and personhood, and according to their review studies show that individuals with severe AD need to be seen as 'a person', e.g. able to socialize with others, lead an unconditional existence with no demands or corrections, be seen by others and be treated as an autonomous person. Persons with severe AD have a hidden personhood not a lost one, and person-centered care supports the person's rights, values and beliefs shown in an unconditional, positive acceptance of the individual ${ }^{[38]}$. The participants in the present study are also each 'a person' and not a different individual despite their disease, which in turn might show parts of the 'hidden' personhood from each of them; something that differs from one person to another, which also may affect their activity day and night. In the present study the participating persons with AD had various reasons for being prescribed visits by the AAT team with a therapy dog besides activity and sleep. These reasons could be for example to improve well-being, harmony and to enjoy a pleasurable moment with the therapy dog. This may need to be further investigated in other ways. This may also indicate that the purpose and use of the trained therapy dog team has not yet been clearly justified and established in the care of older persons with dementia, and not yet in a totally personcentred way ${ }^{[38,39]}$ where the person's need for activity and sleep are taken into consideration. The therapy dog's impact on each person needs to be individually evaluated in respect of both daytime activity and night-time sleep. AAT with therapy dogs in the care of persons with AD or other dementias may, as in the present study, have several goals, for example to activate or deactivate individuals or to decrease anxiety associated with wandering behaviours, as well as to decrease aggressiveness. Edvardsson et al. ${ }^{[39]}$ found that caregivers who involved persons with dementia in participating in everyday activities like e.g. watering plants and preparing coffee in a nursing home enjoy a more frequent person-centered care and a higher quality of life. The prescription for therapy dog visits for each person described signs that might have indicated wandering behaviour and disturbed sleep, but also mentioned a person's interest in dogs, all pointing towards person-centered care. AAT therapy dog team suitability for the individual is based on the fact that the person should have experience of dogs in the past, otherwise the therapy will not be appropriate. For those who are prescribed, the therapy dog 
visits might be seen as a person-centered act, but persons that do not have experience of dogs in life may miss out on this opportunity, and this may have an impact on them both for the moment and in the future. As the use of AAT in the care of persons with AD increases further studies are needed to evaluate the effect in a more person-centred way as well as how the use of AAT with a therapy dog should be used.

\section{Limitations}

To the best of our knowledge this was the first attempt to study the use of an AAT team with a therapy dog following participants during a period of 16 weeks. The number of participants is too low to allow for more advanced statistical analysis and the analysis was made to present results graphically, and a larger number of participants could reveal different results. The results show no clear pattern of effects on individual persons daytime activity and sleep from the visits of the therapy dog, but we have no possibility to say anything about individual clinically effects ${ }^{[40]}$ other than the activity levels. Nevertheless, this study investigated the participating individuals separately and results show a large amount of individual data per minute for 24 hours/day over 16 weeks based on activity curves. The use of an actigraph (Actiwatch ${ }^{\circledR}$ ) was considered an appropriate method to measure the activity of persons with $\mathrm{AD}^{[30,31]}$. Due to the size and weight of the Actiwatch and the fact that it only had to be removed once a month for registering of data it was considered that this method would cause minor interference for the participants. Only a few interruptions in the data in total of 16 weeks were registered, indicating that this instrument was acceptable for these patients. The activity curves clearly showed changes in activity, sleep onset and sleep cessation, with clear recording over an extended period. Someren et al. ${ }^{[29]}$ suggests that recording with the Actiwatch have indicated data reliability, although it is possible that counts lower than 40/minute (which indicate sleep) actually depends on sedentarily due to old age and AD and not necessarily moments of sleep. The person's activity might have been influenced by their environment, for instance by particular events, activities, relatives who brought their own dog or other changes on the ward. However, such activities are in relation to normal activities and normal life of persons with AD living in an institution such as this nursing home. The activity and sleep data shows a great variation. The activity that occurs and shows in the curves, apart from the visits with AAT with a therapy dog, is difficult to explain, but a clear pattern emerges that activity and night-time sleep differ between persons from baseline, during the therapy dog visits and follow-up, despite the individual purpose for each therapy dog visit. As this descriptive study show no clear pattern it is possible that the MMSE (1-17) at baseline could influence the activity both day and night for all participated persons in different ways. The period of baseline was measured for one week which can be seen as a shortcoming, and the baseline might have given more thorough information if it had been longer. In this case the AAT team at the specific nursing home was already established in the nursing home for some years and therefore there was no possibility to interfere or delay the start of therapy dog visits, and the time between the prescription to the AAT-team and the first visit was normally one week. Because of the persons' old age, severe illness and of ethical reasons the research team did not influence the therapy dog team and their work at any way, because this was an already established activity. Further, an ideal situation would have been to have e.g. a larger group of participants, a matched control group, longer baseline period but as the results in this study shows every individual have their own variations and this was in this situation not possible to perform but needs to be considered for further studies within this group of participants. More extensive studies in depth investigations are needed to capture the therapy dogs' impact on activity and night-time sleep for older persons' with AD and other dementias from the individual perspective.

\section{Conclusions}

The present study might contribute to research in the care of persons with Alzheimer's disease and other dementias, and increase understanding of the impact that AAT teams may have on the person's activity during daytime and night-time sleep. The frequency of the visits might need to be carefully adapted to the person's individual needs, and be evaluated both day and night by caregivers that are familiar with the persons' habits and needs. This study contributes to the knowledge about how activity levels vary among persons with AD living in an institution. The study shows no clear 
pattern of effect of encounters with an AAT with a therapy dog but points instead to a great variety of possible different effects between day and night. The results underline the need of further studies to evaluate the effects of using therapy dogs in the care of persons with AD.

\section{Acknowledgement}

The authors would like to thank Sara Runesdotter for statistical support and the following for financial support: Sophiahemmet University, Sophiahemmet Research Foundation, Agria Insurance, SKK Research Foundation, King Gustav V's and Queen Victoria's Foundation, Dementia Foundation, and the Ragnhild and Einar Lundström Foundation.

\section{Conflicts of interest}

The authors declare that there are no conflicts of interest.

\section{References}

[1] Ballard CB, Gauthier S, Cummings J, Brodaty H, Grossberg G, Robert P, et al. Management of agitation and aggression associated with Alzheimer disease. Neurology. 2009; 5: 245-255. PMid:19488082.

[2] Cohen-Mansfield J, Marx MS, Thein K, Dakheel-Ali M. The impact of past and present preferences on stimulus engagement in nursing home residents with dementia. Aging Mental Health. 2010; 14: 67-73. PMid:20155522 http://dx.doi.org/10.1080/13607860902845574

[3] Kverno KS, Black BS, Nolan MT, Rabins PV. Research on treating neuropsychiatric symptoms of advanced dementia with non-pharmacological strategies, 1998-2008: a systematic literature review. International psychogeriatrics / IPA, 2009 ; 1-21.

[4] Graneheim UH, Jansson L. The meaning of living with dementia and disturbing behavior as narrated by three persons admitted to a residential home. Journal of Clinical Nursing. 2006; 15: 1397-1403. PMid:17038100 http://dx.doi.org/10.1111/j.1365-2702.2006.01476.x

[5] Halek M, Bartholomeyczik S. Description of the behaviour of wandering in people with dementia living in nursing homes - a review of the literature. Scandinavian Journal of Caring Science. 2011; 404-413p.

[6] McCurry SM, Reynolds CF, Ancoli-Israel S, Teri L, Vitiello MV. Treatment of sleep disturbance in Alzheimer's disease. Sleep Medicine Reviews. 2000; 4(6): 603-628. http://dx.doi.org/10.1053/smrv.2000.0127

[7] Bliwise LD. Sleep Disorders in Alzheimer's Disease and Other Dementias. Clinical Cornerstone. Neurodegenerative Diseases. 2004; 6: 16-28.

[8] Greenblum CA, Rowe MA. Night time Activity in Individuals with Dementia: Understanding the Problem and Identifying Solutions. Journal of Gerontological Nursing. 2012; 5: 8-11. http://dx.doi.org/10.3928/00989134-20120410-02

[9] Bliwise DL. Sleep Disorders in Alzheimer's Disease and Other Dementias. Neurodegenerative Diseases. 2004 ; 6: 16-28.

[10] Birke L, Holmberg T. Investigating Human/Animal relations in science, culture and work. 2011; (Second edition). Uppsala: University print.

[11] Fine HA. Animal-Assisted Therapy. Theoretical foundations and guidelines for practice. (Third edition) San Diego, CA, USA. 2010.

[12] Baun MM, McCabe B W. Companion Animals and Persons with Dementia of the Alzheimer's Type: Therapeutic Possibilities. American Behavioral Scientist. 2003; 47 (1): 42-51. http://dx.doi.org/10.1177/0002764203255211

[13] Filan SL, Llewellyn-Jones RH. Animal-assisted therapy for dementia: a review of the literature. International Psychogeriatric. 2006; 18(4): 597-611. http://dx.doi.org/10.1017/S1041610206003322

[14] Baton K, McCabe B, Baun MM, Wilson C. The Effect of a Therapy Dog on Socialization and Physiological Indicators of stress in Persons Diagnosed with Alzheimer's Disease. In: Wilson CC, Turner DC, eds. Companion Animals in Human Health. Thousand Oaks, CA: Sage, 1998; 203-215. http://dx.doi.org/10.4135/9781452232959.n13

[15] Churchill M, Safaoui J, McCabe BW, Baun MM. Using a Therapy Dog to Alleviate the Agitation and Desocialization of People with Alzheimer's Disease. Journal of Psychosocial Nursing. 1999; 37: 16-22.

[16] Perkins J, Bartlett H, Travers C, Rand J. Dog-assisted therapy for older people with dementia: A review. Australasian Journal of Ageing, 2008; 27: 177-182. PMid:19032618 http://dx.doi.org/10.1111/j.1741-6612.2008.00317.x

[17] Sellers DM. The Evaluation of an Animal Assisted Therapy Intervention for Elders with Dementia in Long-Term Care. Activities, Adaptions and Aging. 2005; 30: 61-76. http://dx.doi.org/10.1300/J016v30n01_04 
[18] Moretti F, De Rochi D, Bernabei V, Marchetti L, Ferrari B, Forlani C, et al. Pet therapy in elderly patients with mental illness. Psychogeriatrics. 2011; 11: 125-129.

[19] Buettner LL, Fitzsimmons S, Barba B. Animal-Assisted Therapy for Clients with Dementia. Journal of Gerontological Nursing. 2001; 37 (5). http://dx.doi.org/10.3928/00989134-20110329-05

[20] Nordgren L, Engström G. Animal-Assisted Interventions in Dementia: Effects on Quality of Life. Journal of Clinical Nursing Research, 2013; 1-13.

[21] Bernabei V, De Ronchi D, La Ferla T, Moretti F, Tonelli L, Ferrari B, et al. Animal-assisted interventions for elderly patients affected by dementia or psychiatric disorders: A review. Journal of Psychiatric Research, 2013; 1: 1-12.

[22] Fritz CL, Farver TB, Kass PH, Hart LA. Association with Companion Animals and the Expression of Noncognitive Symptoms in Alzheimer's Patients. The Journal of Nervous and Mental Disease. 1995; 183(7): 459-456. PMid:7623018 http://dx.doi.org/10.1097/00005053-199507000-00006

[23] Richeson NE. Effects of animal-assisted therapy on agitated behaviours and social interactions of older adults with dementia. American Journal of Alzheimer's Disease and Other Dementias. 2003;18: 353-358. PMid:14682084 http://dx.doi.org/10.1177/153331750301800610

[24] Churchill M, Safaoui J, McCabe BW, Baun MM. Using a Therapy Dog to Alleviate the Agitation and Desocialization of People With Alzheimer's Disease. Journal of Psychosocial Nursing, 1999; 37: 16-22.

[25] McCabe BW, Baun MM, Speich D, Agrawal S. Resident Dog in the Alzheimer’s Special Care Unit. Western Journal of Nursing Research. 2002; 24(6): 684-696. http://dx.doi.org/10.1177/019394502320555421

[26] Yin RK, Case Study Research, Design and Methods. 2009; Sage Inc. Thousand Oaks, California.

[27] Camtech User Manual. The Actiwatch User Manual. CamNtech Ltd, Cambridge. 2008; Version 7.2, No 30096. 1-67.

[28] Eggermont LHP, Scherder EJA. Ambulatory but Sedentary: Impact on Dognition and the Rest- Activity Rhythm in Nursing Home Residents with Dementia. Journal of Gerontology: Psychological sciences. 2008; 63: 278- 287. http://dx.doi.org/10.1093/geronb/63.5.P279

[29] Someren EJW. Improving actigraphic sleep estimates in insomnia and dementia: how many nights? Journal of Sleep Research. 2007; 16: 269-275. PMid:17716276 http://dx.doi.org/10.1111/j.1365-2869.2007.00592.x

[30] Martin JM, Hakim AD. Wrist Actigraphy. American College of Chest Physicians. 2011; 1514-1527. http://dx.doi.org/10.1378/chest.10-1872

[31] Nagels G, Engelborghs S, Vloeberghs E, Van Dam D, Pickut BA, De Deyn PP. Actigraphic measurement of agitated behaviour in dementia. International Journal of Geriatric Psychiatry. 2006; 21: 338-393. PMid:16534768 http://dx.doi.org/10.1002/gps.1483

[32] Folstein M, Folstein S, McHugh P. Mini-Mental State. A practical method for grading the cognitive state of patients for the clinician. Journal of Psychiatric Research. 1975; 12: 189-198. http://dx.doi.org/10.1016/0022-3956(75)90026-6

[33] Karlawish J, Kim SY, Knopman D, van Dyck CH, James BD, Marson D. The Views of Alzheimer Disease Patients and Their Study Partners on Proxy Consent for Clinical Trial Enrollment. American Journal of Geriatric Psychiatry. 2008; 16: $240-247$. PMid:18310554 http://dx.doi.org/10.1097/JGP.0b013e318162992d

[34] Marx MS, Cohen-Mansfield J, Regier NG, Dakheel-Ali M, Srihari A, Thein K. The Impact of Different Dog-related Stimuli on Engagement of Persons with Dementia. American Journal of Alzheimer's disease \& Other Dementias, 2010; 25 : 37-45. PMid:19075298 http://dx.doi.org/10.1177/1533317508326976

[35] Nordgren L, Engström G. Effects of Animal-Assisted Therapy on Behavioural and/or Phychological Symptoms in Dementia: A Case Report. American Journal of Alzheimer’s Disease \& Other Dementias. 2012; 27: 625-632. http://dx.doi.org/10.1177/1533317512464117

[36] Kongable GL, Buckwalter CK, Stolley MJ.The Effects of Pet Therapy on the Social Behavior of Institutionalized Alzheimer's Clients. Archives of Psychiatric Nursing. 1989; 3(4): 191-198. PMid:2774672

[37] Swall A, Ebbeskog B, Lundh Hagelin C, Fagerberg I. Can Therapy dogs evoke awareness of one’s past and present life in persons with Alzheimer's disease? International journal of Older People Nursing. http://dx.doi.org/10.1111/opn.12053

[38] Edvarsson D, Winblad B, Sandman PO. Person-centred care of people with severe Alzhemer's disease: current status and ways forward. The Lancet Neurology. 2008; 7(4): 362-367. http://dx.doi.org/10.1016/S1474-4422(08)70063-2

[39] Edvardsson D, Petersson L, Sjogren K, Lindkvist M, Sandman PO. Everyday activities for people with dementia in residential aged care: associations with person-centredness and quality of life. International Journal of Older People Nursing. 2013; http://dx.doi.org/10.1111/opn.12030

[40] Frost MH, Bonomi AE, Cappelleri JC, Schünnemann HJ, Moynihan TJ, Aaronson NK, Applying Quality-of-Life Data Formally and Systematically Into Clinical Practice. Mayo Clinical Proceeding. 2007; 82(10): 1214-1228. PMid:17908528 http://dx.doi.org/10.4065/82.10.1214 